\title{
Electronic Medical Record Keeping: Eleven Years Experience at Life Support Eye Clinic, Lagos, Nigeria
}

\section{OO Ogundipe MBBS, FMCO, FWACS}

Life Support Eye Clinic, Lagos, Nigeria

\section{ABSTRACT}

Aim: To report the success of a paperless medical record system in a small clinic in a developing economy and to highlight the advantages and challenges of electronic medical record keeping, even with a small budget.

Method: The concept of electronic med ical record (EMR) as a record keeping method at Life Support Eye Clinic w as born out of necessity in 1998. The ever-growing need for storage space for patients' case files in a small tworoom caravan clinic prompted the move towards a paperless filing method to maximize the available space for clinical proced ures. Tw o com puters were purchased - one for the consulting room and another for the registration desk. An information technology consultant developed the electronic medical record softw are using Lotus Notes and created the network between the two computers using cables. He also trained staff members in the use of the new computer system. That was the beginning of the conversion process from a paper filing system to the EMR system. The time frame of conversion was two years, which was realized in year 2000 .

Results: Life Support Eye Clinic got rid of all paper files for patient records and all patient information was stored electronically with the attending results of faster retrieval of information, ease of follow-up of patients and bill tracking, elimination of mistakes that sometimes occur from bad handwriting, ease of data collation for research purposes, and long-term cost effectiveness, due to elimination of printing and paper costs. Privacy and security of patient information was ensured through the secure computer code to which only authorized staff members had access.

Conclusion: The experience of Life Support Eye Clinic in the use of EMR over 11 years reveals the possibility, benefits, and efficacy of this technologically-advanced method of patient record keeping in a developing country.

Key words: electronic medical records, computer, softw are, privacy

\section{INTRODUCTION}

The system of electronic medical record (EMR) also know as electronic health record (EHR), or electronic patient record (EPR) for record keeping has been available for over forty years, but it is yet to be embraced in Nigerian hospitals. The use of paper filing, with all its flaws, still dominates the record keeping system in most hospitals and clinics. This paper reviews eleven years of use of the EMR system at Life Support Eye Clinic and discusses its benefits over the paper filing system. In an age when going green and recycling is strongly endorsed, it seems the time is ripe for hospitals and clinics in Nigeria to embrace and invest in the EMR system as a more efficient, easy to use method for record keeping.

\section{WHY EMR?}

The advantages of the electronic medical record (EMR) digital filing system over the paper filing system include the following:

- EMR provides the tools needed to track the health of any clinic or hospital business.

- EMR provides instant access to patients' files and clinical details from any location, thereby saving time and improving healthcare coordination.

- EMR makes e-prescribing very easy, facilitates lab orders and viewing of lab results thereby reducing healthcare disparities.

- EMR makes patient follow-up and billing easy and transparent.

- EMR facilitates networking between specialties, resulting in better population and public health.

- EMR facilitates data collection for research purposes.

- EMR tracks billing and makes for efficient accounting and early fraud detection.

- Paper files can get lost making patient information permanently inaccessible.

- EMR facilitates data collation and analysis.

- Tracking of patient information is faster.

- Research and treatment outcome evaluation is facilitated.

- Hard copies can be produced as and when needed. 
- Mistakes can be easily corrected thereby preventing catastrophic situations.

- Records can be encrypted to protect their confidentiality - something that is impossible with paper/physical records.

- It is cost effective in the long run.

\section{LITERATURE REVIEW}

In the 1960s, a physician named Lawrence L. Weed ${ }^{1}$ first described the concept of computerized or electronic medical records. Weed described a system to automate and reorganize patient medical records to enhance their utilization and thereby lead to improved patient care.

Weed's work formed the basis of the Problem Oriented Medical Information System (PROMIS) project at the University of Vermont, a collaborative effort between physicians and information technology experts, started in 1967 to develop an automated electronic medical record system. The project's objectives were to develop a system that would provide timely and sequential patient $d$ ata to the physician, and enable the rapid collection of data for ep id emiological studies, medical audits and business audits. The group's efforts led to the development of the problemoriented medical record, or POMR. Also, in the 1960s, the Mayo Clinic began developing electronic medical record system s. ${ }^{1}$

In 1970, POMR was used in a medical ward of the Medical Center Hospital of Vermont for the first time. At this time, touch screen technology had been incorporated into data entry procedures. Over the next few years, drug information elements were added to the core programme, allow ing physicians to check for drug actions, dosages, side effects, allergies and interactions. At the same time, diagnostic and treatment plans for over 600 common medical problems were devised. ${ }^{1}$

During the 1970s and 1980s, several electronic medical record systems were developed and further refined by various academic and research institutions. The Technicon system w as hospital-based, and Harvard 's Computer Stored Ambulatory Record (COSTAR) system had records for ambulatory care and supported direct patient care, billing and quality assurance programmes like the monitored follow-up of treatment after positive throat cultures for streptococcus. The Health Evaluation through Logical Processing (HELP) system and Duke's 'The Medical Record' are examples of early in-patient care systems. Indiana's Regenstrief record was one of the earliest combined inpatient and outpatient systems.

With advancements in computer and diagnostic applications during the 1990s, EMR systems became increasingly complex and more widely used. In the $21 \mathrm{st}$ century, more and more practices are implementing electronic medical records. In its November 2003 report, "Patient Safety: Achieving a New Standard of Care" the Institute of Medicine in the United States of America encouraged hospitals and physicians to adopt EMRs as a major step towards preventing medical errors. ${ }^{2}$ The complexity of the EMR varies with the provider.

It is vital to distinguish the electronic medical record (EMR) from the Electronic health record (EHR). The Healthcare Information and Management Systems Society (HIMSS) composed a white paper to illustrate the differences in 2006. ${ }^{3}$ The EMR is the legal record created in hospitals and ambulatory environments and it is the source of data for the EHR. The EHR is composed of data from multiple functional EMRs at various care delivery organizations. It thus represents and facilitates the exchange of clinical data and information among stakeholders with in a community, region, or the nation. The stakeholders who share med ical inform ation may include patients/ consumers, healthcare providers, employers, and/ or payers/ insurers, including the government.

A basic EMR is a computer application that may contain patient demographics and clinical data, allow for simple documentation, ordering of prescriptions, and view ing of laboratory and radiology results.

A fully functional EMR is a more robust computer application which contains clinical data, provides support for clinical decision making, uses a controlled medical vocabulary, accepts computerized entry of orders by providers for medications and diagnostic tests, and has other features for clinical documentation. Robust, fully functional EMRs can be used across inpatient and outpatient environments. While using an EMR, healthcare teams document, monitor, and manage health care delivery with in a care delivery organization (CDO). The data in the EMR constitute the legal record of what happened to the patient during their encounter at the CDO, and the EMR is owned by the CDO.

An electronic personal health record ("ePHR") is defined by HIMSS as "a universally accessible, layperson comprehensible, lifelong tool for managing relevant health information, promoting health maintenance, and assisting with chronic disease management via an interactive, common data set of electronic health information and ehealth tools." The ePHR is owned, managed, and shared by the individual or his or her legal proxy(s) and must be secure to protect the privacy and confidentiality of the health information it contains. It is not a legal record unless so defined and is subject to various legal limitations. ${ }^{4}$

Just like any other record keeping, moving patients' records from paper and physical filing system s to computers and their super storage capabilities creates great efficiencies for patients and their providers, as well as health payment system s. But efficiency is not the only ben efit. For ind ividual patients, access to good care becomes easier and safer when record s can easily be shared. Important information such as blood type, prescribed drugs, medical conditions and other aspects of our medical history can be accounted for much more quickly. At the very least, an existing EMR can save time at the doctor's office. At most, quick access to our 
records can be lifesaving if an emergency occurs and answ ers to those questions are need ed during the em ergency decision-making process. ${ }^{5}$

\section{MATERIALS AND METHOD}

Modern technology has provided the capability to store practically any information in digital format, therefore the main material for EMR record keeping is the computer. A minimum of two computers are usually required - the server and the client computer with the appropriate softw are installed.

Computers have become commodities. Today the computer is probably the cheapest piece of electronic equipment you can have in your practice. Software costs vary - free + customization or expensive with extensive capabilities. Most commercially available EMR software focuses on functionalities not relevant to the Nigerian situation.

The concept of EMR as a record keeping method in Life Support Eye Clinic was born out of necessity in 1998 due to lack of space. The ever-growing need for storage space for patients' case files in a small two room caravan clinic prompted the shift tow ards a paperless filing method to maximize the use of the available space for clinical procedures. An information technology professional was approached, who advised the use of a paperless system and developed a customized software using Lotus Notes. All that was needed at the initial stage were two personal computers- one was the server in the doctor's consulting room and the other at the reception desk for billing and administrative purposes - and an IT maintenance technician. There was a two year transition period from paper case files to the EMR digital system. In year 2000, the EMR digital system was fully implemented. The long teething period required was due to the training of members of staff who were not computer literate in 1998 , and the painstaking transfer of records from the paper files onto the computer. It was much easier to register new patients on the computer than transferring old case paper files onto the computer. Today how ever, the use of scanners that read handwritings can make digitalization of paper files less painful. The software maintenance technician was always available during the transition period. The personal computer (PC) netw ork communication between the doctor's room and the $\mathrm{PC}$ at the reception desk is linked with cables (wireless system s are now available). Privacy was ensured by the login code that only authorized users know. Information about the patient is received by the billing clerk before the patient leaves the doctor's room resulting in better coordination between clinical and administrative staff. Safeguards in the form of regular backups prevent any permanent loss of patient $d$ ata and easy in form ation retrieval without the need to flip through numerous pages of paper case files of patients who have many years of record with the clinic.

\section{RESULTS}

Life Support Eye Clinic (LSEC) got rid of all paper files and only occasionally used them when there were computer glitches which was not very often. Daily backup on three and a half inch diskettes were done, so patients' in formation were intact. In 2009, the clinic moved to online backup record storage. Figures 1-4 show the computer demonstration of data capture.

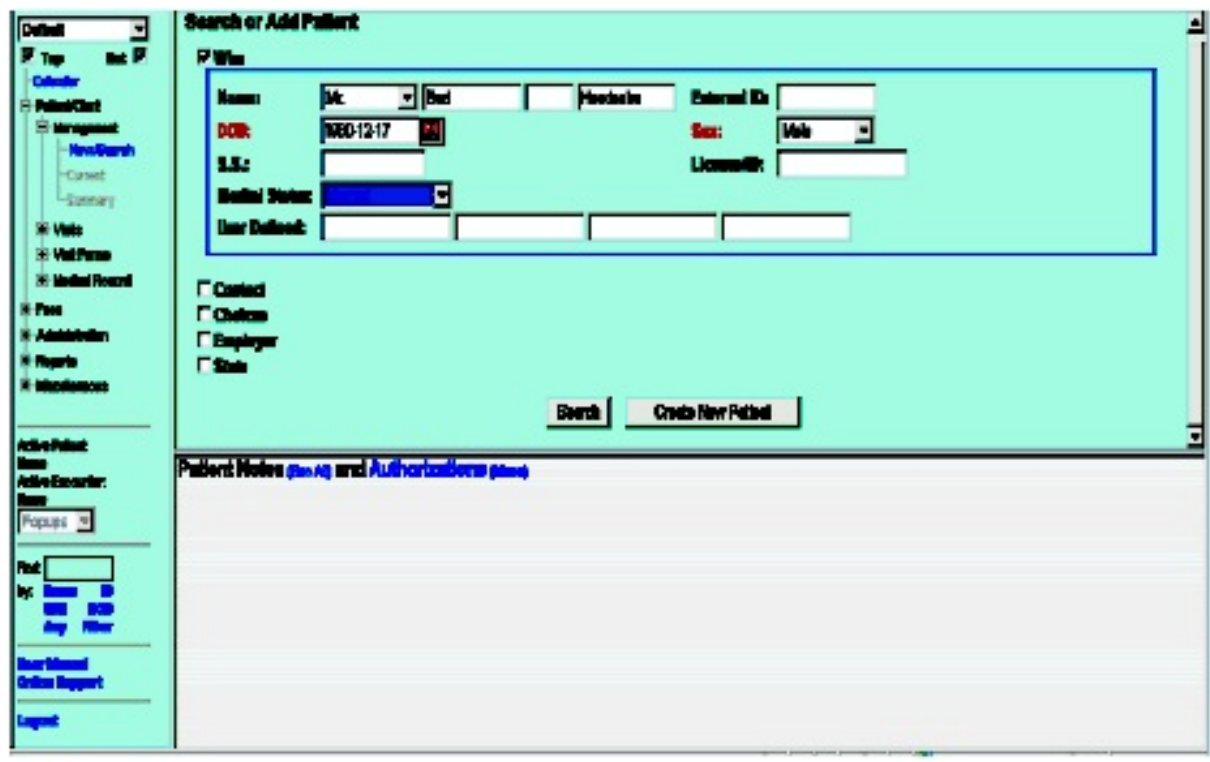

Figure 1. Adding a new patient 


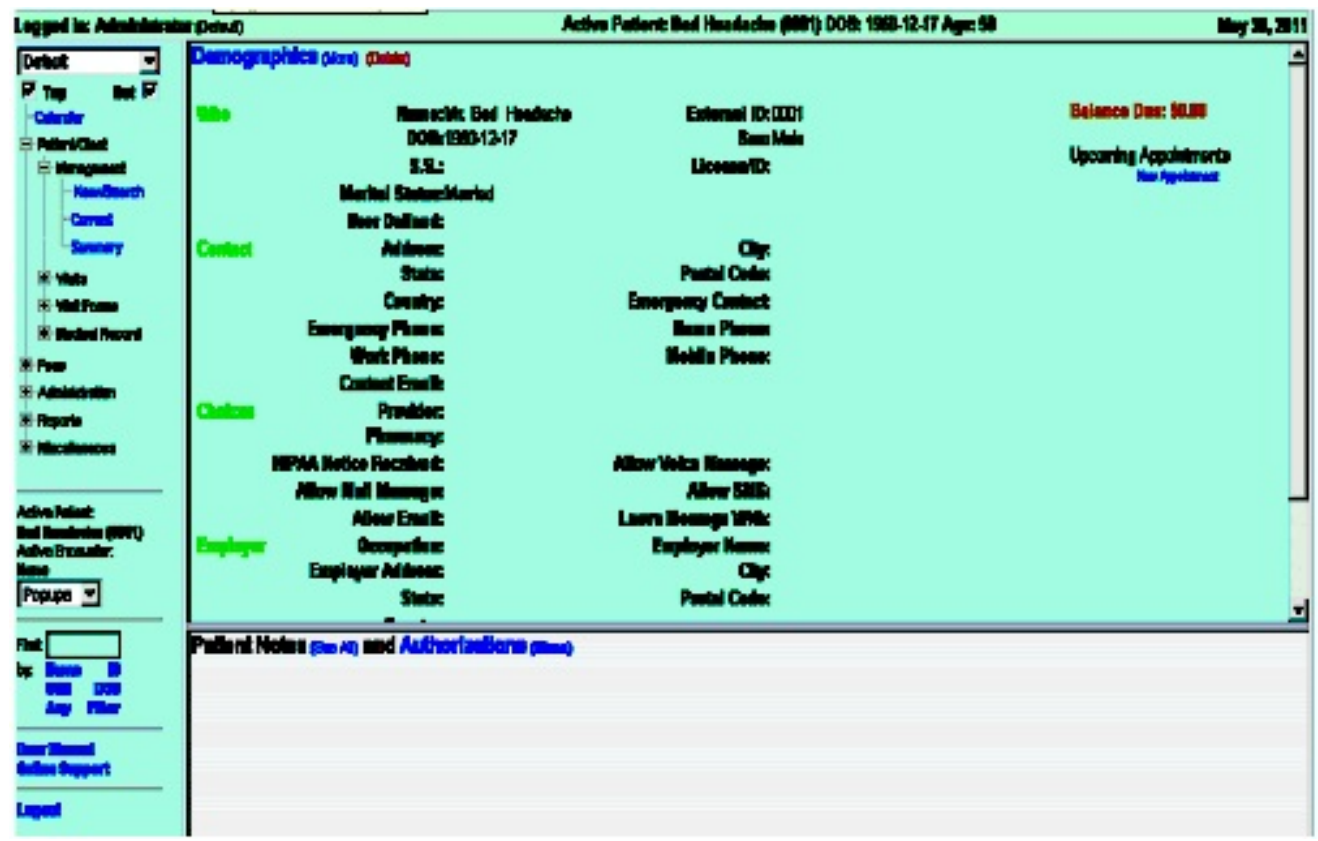

Figure 2. New patient, post-data entry

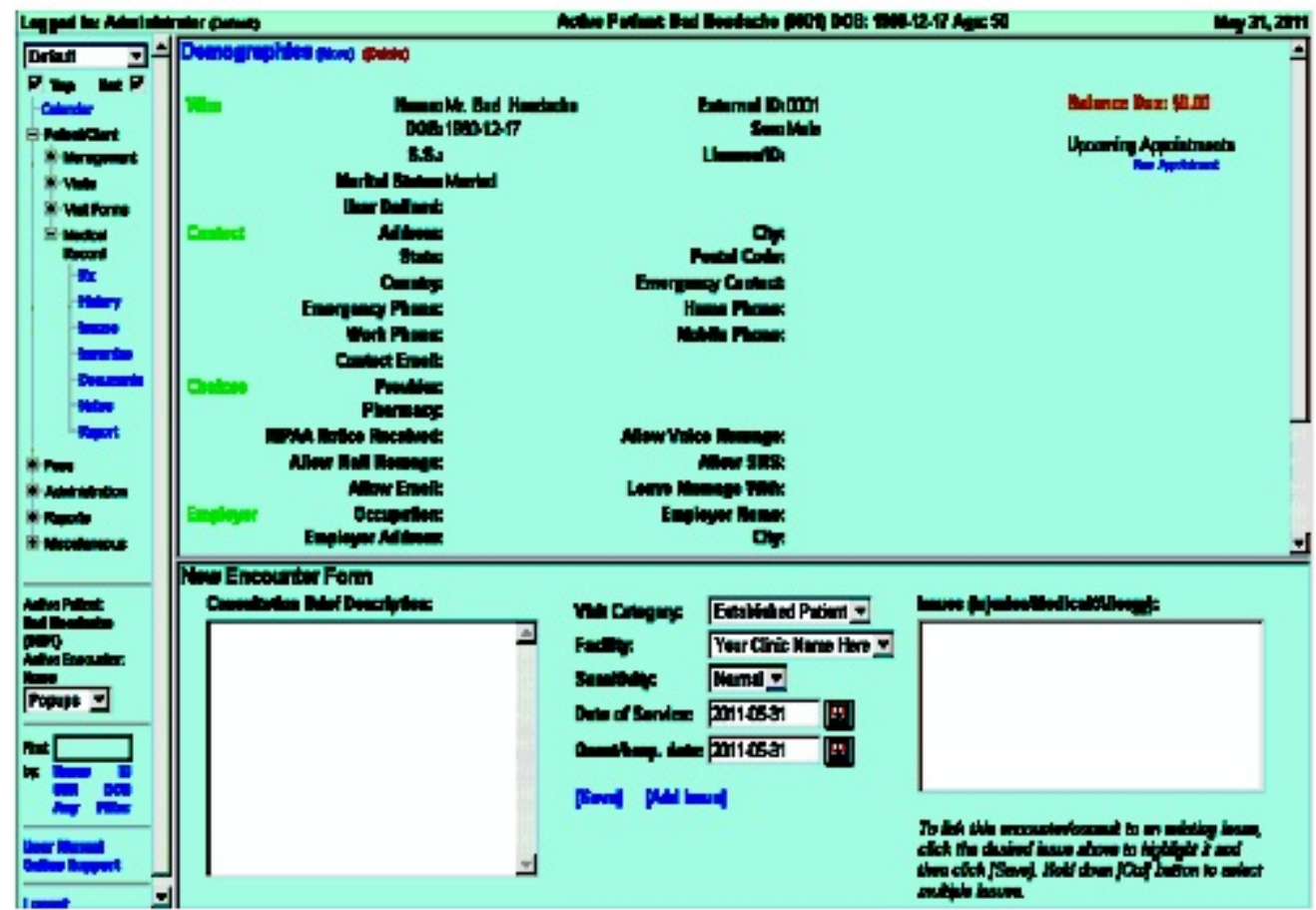

Figure 3. Patient visit data entry screen 


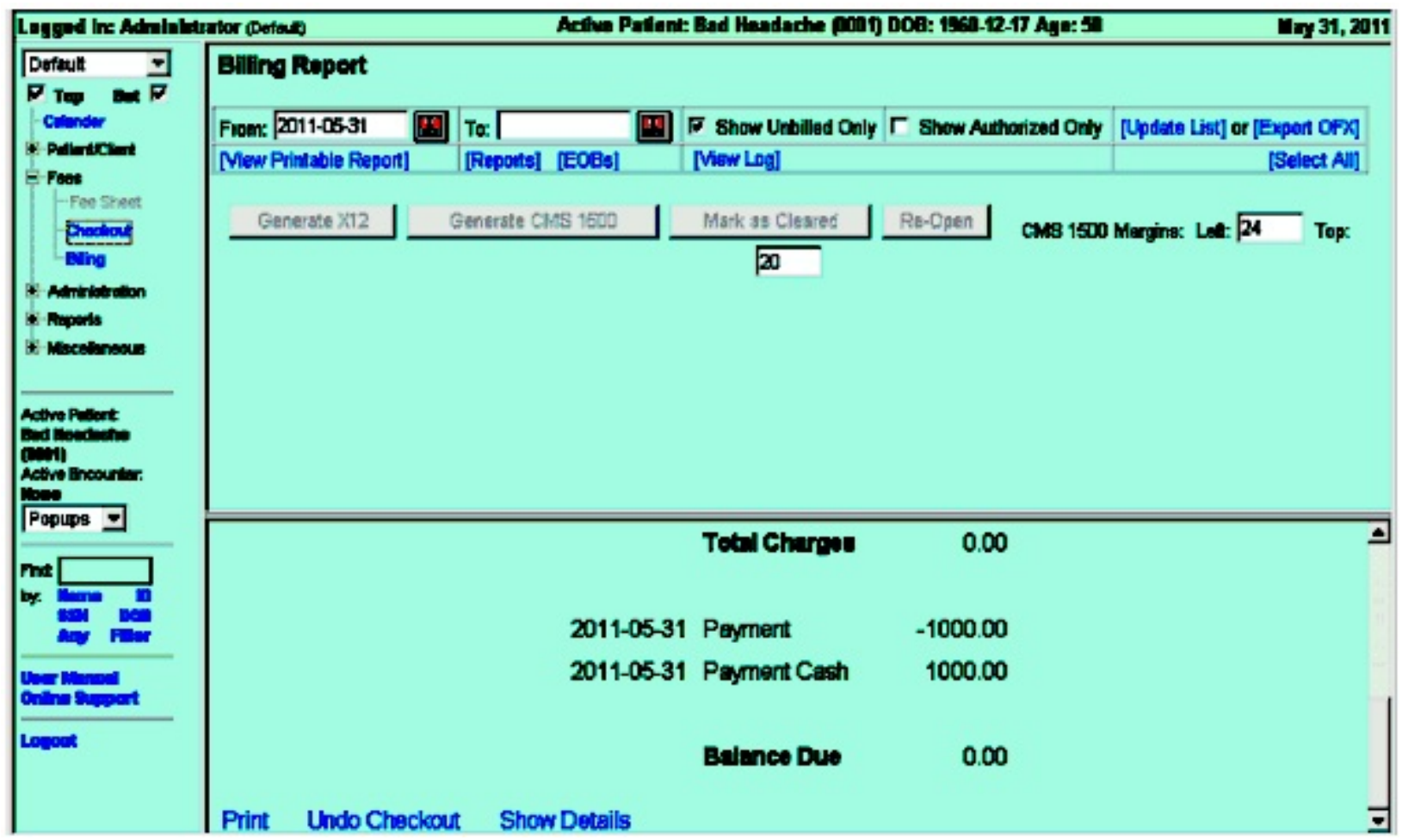

Figure 4. Billing

The challenges encountered were:

- Occasional loss of data due to system failure (i.e. may have to re-enter data for a single patient visit)

- Storage capacity that occasionally needed to be increased

- Learning curve for new staff (if not already computer literate) that slowed down the pace of work.

Life support Eye Clinic has successfully used EMR and eliminated the need for clerical help in filing, retrieving and transporting case files. The need for an in-house IT technician to troubleshoot cannot be overstated. Today, with widespread computer literacy in Nigeria, the transition period will be shorter for any clinic that decides to convert.

\section{DISCUSSION}

The transition from a paper filing system to an EMR system at the Life Support Eye clinic was largely due to a computer system s integrator who simplified the computer program me used in this study resulting in ease of use and prevention of medical errors. Even the US government thinks electronic record keeping is important, and it has put its money and efforts where its recommendations are. Veterans' hospitals across the country in the US share an electronic system, called VistA, which allows for sharing of records for veterans in its health system. Should a patient find himself in a veteran hospital, even while away from home, the hospital will have the same access to his or her records that the hometown hospital does. ${ }^{6}$

Tragic events like 9/11, Hurricane Katrina, and the California fires have showcased the benefits of electronic record keeping. Those injured or made sick by any of those events were more easily treated and may have found better outcomes than those for whom no medical records were available. Large-scale EMR systems replicate their stored records in several places across the country so that one tragic event cannot destroy them. ${ }^{9}$

Chaudhry et al. system atically review ed the evidence on the effect of health information technology on quality, efficiency, and costs of health care. ${ }^{8}$ After examining 257 studies that met the inclusion criteria, quality benefits included increased adherence to guideline-based care, enhanced surveillance and monitoring, decreased medication errors, and decreased utilization of care. The highest quality studies came from 4 academic institutions with their own internally-developed system s, and there was evidence from commercial systems about improvements in quality and efficiency.

Nonetheless, the literature and EMR vendors suggest there are several benefits. Miller and Sim note that the path to quality improvement and fin ancial benefits lies in getting the greatest number of physicians to use the EMR rather than paper for as many of their daily activities as possible. The key obstacle in this path is the extra time it takes 
physicians to learn to use the EMR effectively for their daily tasks. ${ }^{7}$

The experience of Life Support Eye Clinic confirms this tortu ous learning curve which most physicians may want to avoid but is rew arding in the long run. Potential benefits in quality and efficiency are only realized if all relevant data are included in the EMR. If most in formation is documented in the electronic chart, but the patient's allergies or medications are recorded on paper, there is a potential for adverse medical events.

Another benefit is safety. In the past, the way a doctor obtained your health history was by asking you. Each time you visited a new doctor's office, you filled out form s about your history, including previous surgeries, or the drugs you take on a regular basis. If you forgot a piece of information, or if you did not write it down because it seemed unimportant to you, then your doctor did not have that piece of your medical puzzle to work with.

However, when doctors share records electronically, your new doctor only needs to ask your name, birth date, and possibly another piece of identifying information. $\mathrm{He} /$ she can then pull up your records from their electronic storage space. All of the information needed will be there in full. Diagnosis and treatment decisions might be altered based on information retrieved digitally, which is far more complete than what you might have written down on paper. In the past, when a doctor closed his practice, retired, moved, or even died, patient record s could easily get lost or relocated, making it impossible for patients to get the records they need ed to take to a new doctor. Keeping these record s electronically, especially in the cases where patients can also gain access to them means the patient will not be left without the records he/ she may need.

Money is also saved by using electronic medical records; not just the cost of paper and file folders, but the cost of labour and space, too. In any business, time equals money. The efficiencies created by simply typing a few identifying keystrokes to retrieve a patient's record as op posed to staring at thou sands of file fold ers, filing and refiling them saves a doctor's practice or a hospital many thousands of dollars, that is even after taking the cost of the electronic system into account. Efficiencies put in to play by doctors and insurance companies to save money eventually lead to patients saving money too. There are however barriers to the adoption of EMRs. The two most common factors that impede the ad option of EMR in private practices are early start up costs and uncertain financial gains according to a 2004 study by Miller and Sim. ${ }^{7}$ EMR price tags range widely, depending on what is included, how robust the system is, and how many providers use it. Asked what is paid in an online survey, about a third of respondents paid between $\$ 500$ and $\$ 3,000$ per physician. Another third paid between $\$ 3,001$ and $\$ 6000$ and 33 percent paid more than $\$ 6,000$ per physician for their EHR. ${ }^{10,11,12}$

The cost of transition at the Life Support Eye Clinic w as the cost of computers, the cost of computer software ad op ted and the income of the IT technician. Computers and computer soft ware are much cheaper in Nigeria tod ay than in 1998 and there are more IT technicians in the market today, which means better bargaining power. These translate to much reduced cost of transition for a clinic in Nigeria today.

Physicians in the United States of America tend to see at least a short-term decrease in productivity as they implement an EMR. This is because they spend more time entering data into an empty EMR than they spend updating paper charts with simple dictation. Such hurdles were overcome by the modification of the softw are by the system s integrator of Life Support Eye Clinic, thereby reducing the complexity of data entry to suit the clinic's need.

In conclusion, the impact of technology on clinical care processes in the past five decades has been presented. The experience of Life Support Eye Clinic in the use of EMR over eleven years reveals the possibility, benefits and efficacy of this technologically-advanced method of patient record keeping in a developing country.

\section{ACKNOWLEDGEMENTS}

I wish to thank my husband, whose encouragement and hard work developing the software we have used successfully over the past eleven years at the Life Support Eye Clinic, made this paper possible. He also contributed to the technical writing of this paper.

\section{REFERENCES}

1. Fitzmaurice JM, Ad ams K Eisenberg JM. Three decad es of research on computer applications in healthcare: medical informatics support at the agency for healthcare research and quality. $J$ Am Med Inform Assoc 2002;144-160.

2. Aspden P. Corrigan JM, Wolcott J, Erikson SM. Patient Safety : achieving a new standard of care. Washington DC: National Academy Press 2004

3. Garets D, Davis M. Electronic Medical Records vs. Electronic Health Records: Yes, There Is a Difference. A HIMSS Analytics ${ }^{\mathrm{TM}}$ White Paper. Updated January 26, 2006. Accessed: October 1, 2008.

4. HIMSS Board of Directors. HIMSS Personal Health Records, Definition and Position Statement. Healthcare Information Management and Systems Society (HIMSS). Accessed: October 1, 2008

5. Trisha Torrey. Prepare for ICE : In Case of Emergency. Helping Medical Personnel Get the Information They Need to Treat You.

http:/ / patients.about.com/od/ electronicpatientrecords / a/ emr.htm Updated in April 092010

6. VISTA Monograph. United States Department of Veteran Affairs : Veterans Health Information Systems and Technology Architecture (VISTA) http:// www4.va.gov/vista_monograph/ Retrieved 20107-01 
7. Miller RH, Sim I. Physicians' use of electronic medical records: barriers and solutions. Health Affairs 2004; 23(2): 116-126.

8. Chaudhry B, Wang J, Wu S, et al. Systematic review: impact of health information technology on quality, efficiency, and costs of medical care. Ann Intern Med 2006; 144: 742-752.

9. Shekelle PG, Morton SC, Keeler EB. Costs and benefits of Health Information Technology. Evidence Report/ Technology Assessment No. 132. (Prepared by the Southern California Evidence-based Practice Center under Contract No. 290-02-0003.) AHRQ Publication No. 06E006. Rockville, MD: Agency for Healthcare Research and Quality. April 2006.
10. Moore, Pamela (2008). "Navigating The Tech Maze". Physicians Practice.

http:/ / ww w.physicianspractice.com/ index/ fuseaction / articles.details/ articleID/ 1214/ page/ 1.htm. Retrieved 2009-08-23

11. Gabriel, Barbara (2008). "Do EMRs Make You a Better Doctor?". Physicians Practice.

http:/ / www.physicianspractice.com/ index/ fuseaction / articles.details/ articleID/ 1203/ page/ 1.htm. Retrieved 2009-08-23.

12. Diana Manos, Electronic health records not a panacea, Healthcare IT New s/ MIMSS California, Monograph Dec. $14^{\text {th }} 2009$. 